

Annales UMCS Informatica AI 8(1) (2008) 165-175

10.2478/v10065-008-0016-2

Annales UMCS

Informatica

Lublin-Polonia

Sectio AI

http://www.annales.umcs.lublin.pl/

\title{
Wireless sensor networks for structural and environmental monitoring
}

\author{
Igor Dunajewski* \\ Institute of Environmental Mechanics and Applied Computer Science, \\ Kazimierz Wielki University, Chodkiewicza 30, 85-072 Bydgoszcz
}

\begin{abstract}
The article discusses various applications of Wireless Sensor Networks (WNS) in environment and civil engineering constructions monitoring with a particular emphasis on the evaluation of the influence of individual node failures on the operation of the whole network.

The dynamic development of civilization more and more necessitates the use of applications of integrated measure and control systems enabling constant monitoring and tracking of environmental conditions as well as industrial and civilian constructions in real time. Appropriate measurements of relocations and deformations of geotechnical and hydrotechnical structures have a key significance for ensuring safety precautions and their appropriate use and operation.

The article explores possibilities for the application of WNS's in the above fields. WNS networks make it possible to monitor engineering constructions, to keep track of any changes occurring in buildings and structures and their immediate surroundings, to measure the settlement and vertical dislocation of structures or surfaces, or to monitor land-slips of bridges, tunnels or road embankments. Information collected by sensor networks is reported and dispatched progressively from measure points (nodes) providing accurate description of abrupt or gradual changes in the state of a building and the conditions of the surrounding area. However, due to harsh environmental conditions, unattended operation and unique characteristics of WSN's, sensors are subjected to various hazards and risks. It is pointed out in the article that those features that decide on the practicality and applicability of the networks are at the same time instrumental in the vulnerability of the system or that their application involves a risk of purposeful malicious actions aiming at disruption of the whole monitoring system.
\end{abstract}

\section{Introduction}

A natural consequence of the civilization progress is the increase in the number of various and diversified buildings and engineering structures. Regardless of the technologies applied or material used, the risk of an unwanted failure that may bring about serious consequences has to be increasingly taken into consideration.

\footnotetext{
*e-mail address: diset@interia.pl
} 
Structural Health Monitoring (SHM) is a rapidly developing field of science. One can claim that the SHM-based systems are, in a way, further development of periodic on-site inspections and maintenance aimed at evaluating the condition of a structure under scrutiny. SHM methods enable us to constantly monitor the technical condition of a structure and make it possible to introduce indispensable measures to remedy any threats to the structure as well as to localize a damage fast and precisely. An early detection of a damage and unequivocal evaluation of the degree of wear and tear of a structure may prevent any unwanted accidents or disasters. Hence, the need for solutions that would ensure constant evaluation of the technical condition of industrial structures that pose threat to people and natural environment is getting more and more important and has become a simple modern necessity. Besides safety reasons, SHM allows to optimize maintenance costs of engineering structures. Instead of, often inefficient, periodic post-construction overhauls one can focus on remedying real damages and on efficient modernization works based on the real knowledge of current technical condition of a structure. An overhaul is conducted not only according to a pre-defined schedule but when there is a real need for it. SHM is more and more often taken into consideration as early as at the designing stage of a structure, which ultimately gives best results.

The problem of the risk of a failure occurrence also applies to, even more so, older structures built without SHM application. The deterioration of buildings and structures becomes more advanced with time and effects in the deterioration of their parameters increasingly influenced by the intense use. This is particularly visible in the case of infrastructure and road constructions. Monitoring of these structures, often based on on-site examination only, is not enough to meet modern requirements in the field. Therefore, it seems perfectly reasonable to try to introduce constant monitoring procedures to engineering structures. In addition, a detailed knowledge of the record of parameters can be also used at the early stage of designing structures in the future. The usefulness of the application of SHM has also been proved by the history of tragic building disasters that could have been prevented if an effective constant monitoring had been previously applied.

\section{SHM methods}

Structural Health Monitoring methods are based on Non-Destructive Inspection (NDI). Generally, there are global SHM methods used for monitoring the whole of a structure and local methods used for monitoring only the most sensitive spots. An application of both methods combined together seems to be the most effective solution [1]. SHM's used to detect damages to civil engineering buildings and structures are mainly based on the analysis of 
mechanical properties of a structure. They can also be based on the analysis of static quantities such as bendiness, twistiness, lengthening or tension to occur in a structure under given conditions. Their relatively simple implementation is undoubtedly one of their main advantages, though one has to admit that they do not secure sufficient precision needed for the purpose. Nowadays many expectations are placed upon those SHM methods that are based on the phenomenon of the propagation of surface acoustic waves (Rayleigh waves, Lamb waves). However, a serious problem here is how to generate a highfrequency wave in a massive building with stiffness and inelastic, unrecoverable or permanent, deformation capacity and how to differentiate the return of the wave from a damaged spot or the edge or inlinearity of a building. Low frequency methods based on the modal model seem to be a good SHM solution to be applied in civil engineering buildings and structures. Diagnostic methods based on the modal model involve a comparison of a given value identified for a structure in safe and undamaged condition to the current value obtained by sensor devices. If any differences occur, they indicate a possibility of a damage to the structure. There are many sub-groups of the method such as those based on the changes in the frequency characteristics of a system, changes in the derivatives' value of the system of vibration, damage-induced changes in Ritz vectors, changes in dynamic susceptibility, changes in the nature of vibrations (MAC) or the adjustment of the finite element model [2,3]. The problem that arises, however, is the absence of appropriate data for a model in undamaged condition. The most commonly used techniques for a determination of parameters for the modal model are: Experimental Modal Analysis (EMA) and Operational Modal Analysis (OMA) [4].

In the past, while taking measurements during an on-site inspection, the results of the measurements were to be obtainable from sensor devices in a laboratory or from sensor devices located in a given structure. With the case of a constant SHM, measuring devices are deployed in a location where they are most effective and are its integral part. To ensure continuity of a SHM, the communication has to be made continuous or always accessible when needed. In traditional solutions, sensor devices are connected by a wire network. Nowadays, the wireless network communication technology is increasingly common [5]. These technologies can be based on WLAN, GSM networks, on radiomodems or on WSNs. The latter technology will be more broadly discussed further on in the article.

\section{Wireless technology}

Wired continuous monitoring entails significant financial outlays. Traditional and conventional sensors, signal conditioners and, first of all, cabling - all this 
requires substantial financial resources available. For instance, the total investment cost of the wired system consisting of 55 vibration, compression, torsion, temperature and dampness integrated sensor devices installed on the Oresund strait bridge amounted to 2,000,000 euro. This is one of the biggest bridge crossing in Europe. Especially because of a large size of an engineering structure and the ensuing necessity of installing wires with considerable length, the implementation of wireless systems seems to be perfectly justified. The situation is much more favourable when the continuous monitoring system is already taken into consideration at the designing or planning stage and then installed during the construction work than where there is a need for this installation in an already existing structure. In the latter case, mounting wires may effect in considerable difficulties as some of the provisions of monitoring may not be possible to be implemented. The application of the technology based on wireless transmission is not only most cost-effective but also enhances and makes simpler the installation of the diagnostic system [6].

Many particular possibilities that wireless technology has been offering over the past few years in solutions based on WSN's are increasingly gaining global acceptance and interest. These are networks consisting of small, usually autonomous, devices armed with different kinds of sensors. These devices with measuring devices are called nodes. Apart from the measuring function, nodes also perform the processing and the communication functions [7,8]. Sensor networks are a fast-developing area in electronics and IT-related sciences, which is followed by even greater possibilities of creating new, more efficient and costeffective measuring and diagnostic systems. A module-based structure of efficient and cost-effective systems makes it possible to connect to the measuring device many different sensors, both analogue and digital. This, in turn, makes sensor networks cheaper and more flexible option [9]. Additional advantages result from the fact that the solutions based on WSN have many adaptive capabilities in diversified working conditions and are capable of transmitting and forwarding data over large distances. A number of civil engineering structures does not have constant monitoring systems implemented or is located far away from human settlements. The above mainly applies to bridges, viaducts, or natural formations such as landslides, slopes, areas prone to flooding or avalanches. Parameters of many of such places can be transmitted to one monitoring unit that is responsible for the technical condition of these structures in a given area.

\section{Structural health monitoring of bridges}

A particularly threatened group of civil engineering constructions includes bridges and viaducts. Over the past few years, a rapid increase in overland 
traffic, including vehicular traffic, has been clearly identified. Not only the number of vehicles grows steadily but also the maximum total weight authorized and the velocity. The majority of civil engineering constructions were built in the past with different assumptions in mind as far as the intensity of their subsequent use and operation are concerned. Vehicles exceeding standards are particularly destructive for road surfaces and their share in general traffic has been growing on drastically. Engineering structures are not ready to endure and sustain the present day heavy traffic with high vehicle-bridge dynamic interaction. In view of the above, structural health monitoring of bridges has become a more and more appropriate solution [10].

There are 183 large bridge structures with the length of over 200 meters in Poland. Additionally, there are 29,000 bridges that can be classified as medium size or small with a collective length of over 540,000 meters. Nearly 60 per cent of these structures is older than thirty years and every fifth was built more than sixty years ago. Despite continuing slight upward trend in technical condition of bridges in Poland, more than 21 per cent of them has been graded below Category 3, i.e. show damages that when neglected result in substantial shortening of their failure-free service. On the other hand, however, continuous overhauls and renovation works carried out on-site eat up large sums of money [11].

The reasons behind the deterioration of the parameters in bridge constructions can be categorized into two groups. The first group includes specific features of material and physical conditions such as torsion, compression and thermal expansion of material, thermal fluctuation effects, or environmental aggressiveness. The other group includes mechanical and strength properties such as severe overload of engineering constructions, wrong static scheme or uneven ground subside or erosion of the river bed. In traffic conditions the biggest threat for bridge constructions is carbon dioxide, chlorides (from using salt for winter road maintenance) and sulphurs (from exhaust fumes). In addition, continuous operation in changeable weather conditions has also to be taken into consideration - in Poland, for example, temperature crosses zero degree about a hundred times per year [11]. Another substantial threat is the process of internal corrosion, which is an important factor in the occurrence of local damages, and may effect, in case of its aggravation, in the loss of the load bearing capacity of structures. Changes that lead to the loss of properties of construction materials reach deep into the structure exerting the most effective influence. Damages to the microstructure cause destructive agents penetrate elements of a construction that eventually lead to zonal changes [12]. A detailed determination of destructive processes involved with the help of SHM can much improve the safety level and bring measurable economic effects. 


\subsection{WSN application}

In the application of WSN's for health monitoring of bridges and viaducts the typical energy constraints for sensor nodes are not always that strict. Usually, there is a possibility to replace batteries or to implement some alternative power supply (solar energy or wind energy) [13]. Additionally, especially with large engineering constructions, access to structured wiring system that can also be used for supplying power to some of the nodes, such as communication nodes, is possible.

The bulk of the applications of WSN's for structural health monitoring of engineering constructions clearly defines the location of nodes and consequently, they can be easily addressed according to their location. Therefore, it is possible to determine in advance the most favourable data transmission or forwarding path. This, in consequence, makes it possible to determine the most favourable use of the energy available. Moreover, a sensor network can be divided into clusters in which data from a group of nodes belonging to a cluster are consolidated by the communication node. The node is responsible for the consolidation of data and for transmitting data to the base station. Commonly used routing algorithm for WSN's that divides a sensor network into clusters is the LEACH algorithm. This algorithm not only divides the network into clusters but also selects and defines communication nodes. With the assumption that the network is homogenous, in each round - due to energy resources - another communication node should be established [14]. In SHM WSN applications it is possible to modify the algorithm and to establish permanent privileged nodes that serve as communication nodes.

Structural health monitoring of bridges can be performed in discontinued work cycles. Measurement-taking cycles can be dependent on the characteristics of service loads and measurements can be taken during the highest intensity of traffic. Since changes in the parameters of a construction usually do not occur rapidly in time, this can even be a period up to several hours. With this assumption, however, an emergency algorithm that in the case of emergency initiates the operation of the system has to be taken additionally into consideration. In practice, this entails a necessity of more frequent measurements to be taken without a necessity, however, of transmitting measurement data to the base station. Nodes can store the data in data cache and send it, apart from scheduled time, only after the predefined emergency threshold has been exceeded. Communication nodes cannot remain long in a dormant state in order to be ready to transmit alarm signals in the case of emergency. Also, the communication between nodes has to be securely maintained in an emergency. 


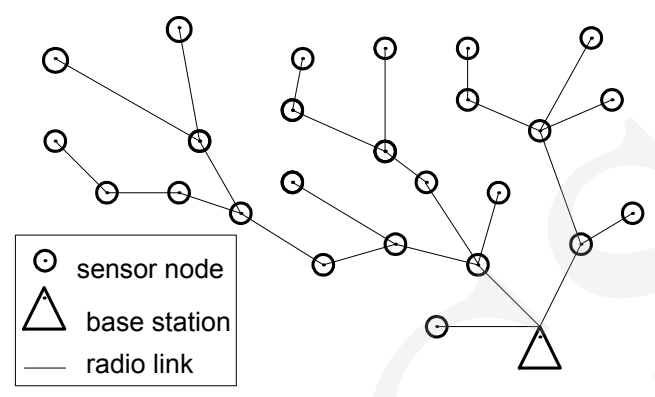

Fig. 1. Sample sensor network

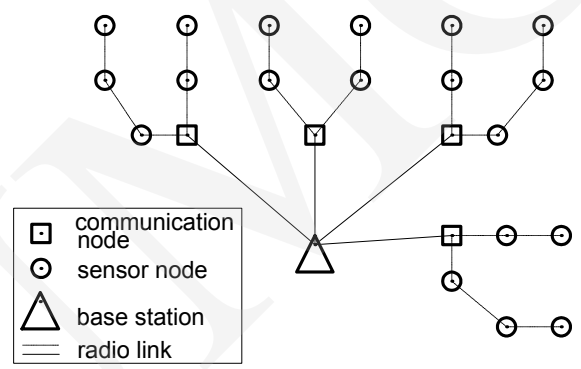

Fig. 2. Sensor network with communication nodes

Another solution to be considered is the one in which individual measurement nodes do not have to send each of measurement readings taken if it does not record changes. However, controlling information (message) that changes have not actually occurred has to be sent to the destination nodes. If this information is much shorter than the regular updates of measurement data packets, then this will effect in the energy saving procedure. If this message is missing, this may effect in a situation in which a node fails to send changed measurement readings due to a failure in the system and it will be interpreted as confirmation of unchanged data. Transmission of data has to be performed in a secure and unequivocal way.

An important problem is the timing of the synchronization of measurements. Since no rigid connection is maintained, synchronization mechanism and measurement data transmission are to be taken into consideration. The obstacle that might appear is, for instance, the influence of temperature on the operation and synchronization of the clock signal for the controllers of the nodes. From among different solutions to this problem, transmission of synchronization signal or PPS (Pulse Per Second) signal are just a few examples [5]. 


\subsection{Structural health monitoring applied in structures under construction}

Modern technological means available make it possible to construct large-size concrete structures within short time. An important problem involved here is cement hydration reaction, which is an exothermic process. Tensions resulted in the course of the process can cause dangerous cracks in the construction. With defined support conditions and specified material, the temperature field allows to unequivocally determine high or low tension state. By comparing the results obtained from measurements with those obtained from a computer simulation, one can unequivocally determine and establish monolithic properties of a structure [15].

An application of a make-shift wired installation in structures under construction is rather troublesome and frequently not even impossible, whereas collecting readings from probes and sensors on-site is time-consuming and sometimes dangerous (when, for example, the probe is mounted on a pylon).

WSN nodes can operate when there is no physical access to them. Hence, they can be inserted into concrete mass. Such a solution makes it possible to monitor the technical condition of a concrete structure in its making. The application of wireless sensors inserted into a concrete block enables the construction workers to monitor temperature in online mode. Though the installation is intended to prevent the structure from overheating, nodes implemented for this purpose must be characterized by the increased resistance to temperature.

\section{Environmental monitoring}

Forecasting natural disasters is not easy as these phenomena are unforeseen and random incidents and cannot be predicted in advance. However, because of sheer security precautions and severe economic losses they may bring about, continuous monitoring and tracking of natural disasters have been perceived as more and more needed and required in today's world. WSN-based monitoring systems are used, for example, for monitoring water levels in rivers and lakes, meteorological changes, changes in the humidity of soil, tsunami warning systems or earthquake warning systems [16-18]. An example of the application of sensor networks for natural environment monitoring can be the project of the area monitoring of El Reventador volcano in Ecuador [19]. Seismic and acoustic sensor devices that provide information on the volcano's activity have been deployed in its close vicinity.

Environmental monitoring usually entails a necessity of taking measurements over a wide area. To do this successfully, homogeneous networks, typical of WSN's, are applied. More often than not the application of this kind of a network is not only the most favourable solution but also the only possible one 
as it is hard to install a wired network in a crater of a volcano or in rainforests. Even in those applications that offer alternative solutions such as, for example, in the monitoring of landslides or slopes in built-up areas, wireless sensor networks are in many cases the most optimal solution.

In networks that are used for monitoring more often than not there is no possibility to replace the power supply or this operation is extremely difficult. Therefore, the management of the network resources is absolutely essential for the duration of proper operation of such networks. One of the most important parameters influencing the energy consumption and the life span of a network is the frequency of measurement taking and data transmission to the base station. The fewer measurements the longer a given construction or a given area will be monitored. On the other hand, it is important to maintain furnishing data or updates within a specified time in which they are still up-to-date.

Many solutions aiming at optimization of the operation of the network and its durability have been proposed [20-22].

\section{Security issues}

The issue of security in the WSN-based distributed measurement systems has become thus increasingly topical and relevant. Short life span and small value of a single piece of information could suggest that there is no need for hard protection of a system. However, the growing number of malicious attacks has made people aware that there really is a need for the introduction of a more rigorous and hard security policy. Various attacks carried out on existing networks have proved that the issue is indeed topical. One of the most spectacular attacks was the one that was carried out on the security system of Davise-Besse nuclear power station, US in 2003, followed by the attack on the signalling and controlling system of the rail system in the USA and then, a year later, in Australia [23]. There have also been numerous smaller incidents of successful attacks. It seems obvious then that distributed measurement systems based on WSN just as well require in many instances a high level of security. This, however, because of the particular properties of WSN's, is rather difficult.

Threats resulting from deliberate and purposeful attacks mostly depend on the tasks a given network has to perform. There is, however, another type of threat common to most of networks. This threat involves failures of individual nodes in a network, which is absolutely essential as such failures may eventually lead to the loss of the usefulness or operability of the whole of a network. Within this area, three types of wireless sensor networks can be distinguished: LND (Last Node Die) network where the network topology is maintained as long as at least one node of the network operates despite dead node emergencies in the network. In HNA (Half Node Alive) networks it is assumed that for proper functioning of 
the network more than a half of working nodes has to be operating, whereas in FND (First Node Die) networks all nodes should be in working order [14]. The latter type of a network is used in many applications of wireless sensor networks related to SHM. Thus, mechanisms that protect the nodes from failures are to be introduced. In a situation when there is a failure to any of the nodes, one has to take into consideration not only alternative path finding algorithm, provided by routing algorithms at the level of the network layer, but also a mechanism for the correction of the results of the measurements. If there is such a possibility, the function of a damaged node can be overtaken by a neighbouring node though measurement data change and the fact has to be taken into consideration in the controlling module. Failures or malfunctioning of one of the sensors can be remedied by, for instance, an artificial neural network used in the measurement centre. Works on such a solution are being conducted nowadays at UCI University in California.

\section{Conclusions}

Rapid development of wireless sensor systems provides ample possibilities for the implementation of this technology. Solutions based on WSN's are inexpensive and exceptionally flexible. They do possess, however, substantial constraints and are prone to various threats that are to be taken into consideration during the planning and designing stages of WSN-based measuring and diagnostic systems. Structural Health Monitoring of engineering structures and constructions as well as environmental monitoring with the application of WSN's can help solve many essential problems related to the security, economic and research aspects of their development. In Poland, there is a wide scope for WSN's implementation, particularly in monitoring civil engineering constructions such as bridges and viaducts. These applications will bring measurable benefits both for administrators of those structures and for their users.

\section{References}

[1] Mendrok K., Comparison of Damage Detection Methods in Aspect of Their Automation Ability. Diagnostyka, 3(43) (2007).

[2] Sohn H., Law K. H., Extraction of Ritz Vectors from Vibration Test Data. Mechanical Systems and Signal Processing, 15(1) (2001) 213.

[3] Farrar C. R., Doebling S. W., An overview of modal-based damage identification methods. Proceedings of DAMAS Conference, (1997).

[4] Mendrok K., Damage Detection of the Viaduct with Use of the Modal Analysis. Diagnostyka, 2(38) (2006).

[5] Bojko T., Chmaj G., Wireless Measurement System. Diagnostyka, 3(39) (2006).

[6] Nawrocki W., Rozproszone Systemy Pomiarowe. Wydawnictwa Komunikacji i Łączności, Warszawa, (2006), in Polish. 
[7] Akyildiz I. F., Su W., Sankarasubramaniam Y., Cayirci E., A Survey on Sensor Networks. IEEE Communication Magazine, August (2002).

[8] Karl H., Willig A., A Short Survey of Wireless Sensor Networks. TKN Technical Report TKN-03-018, Technical University Berlin, October (2003).

[9] Kiefer K. F., Krug E., Ajupova G., Walter P.L., Wireless Sensors Applied to Modal Analysis. XXI IMAC Proc., (2003) 253.

[10] Lynch J. P., Law K. H., Kiremidjian A. S., Farrar E., Sohn H., Allen D., Nadler B., Wait J., Laboratory and Field Validation of a Wireless Sensing Unit Design for Structural Monitoring. Proceedings of the US-Korea Workshop on Smart Structural Systems, Pusan, Korea, August (2002).

[11] http://www.gddkia.gov.pl/article/drogi_i_mosty/mosty

[12] Owsiak Z., Ocena stanu betonu w elementach wiaduktu drogowego. Przegląd Budowlany, 5 (2007), in Polish.

[13] www.perpetum.com

[14] Handy M. J., Haase M., Timmermann D., Low Energy Adaptive Clustering Hierarchy with Deterministic Cluster-Head Selection. IEEE, (2001).

[15] Witakowski P., Technologia budowy konstrukcji masywnych z betonu. XII Konferencja Naukowa, Korbielów, (2001).

[16] Tilak S., Chiu K., Quinn G., Fountain T., Baru C., The Case for Mobile Devices in Environmental Observing Systems. The 4th ACM Conference on Embedded Networked Sensor Systems, November (2006).

[17] Eisenman S.B., Ahn G.-S., Lane N.D., Miluzzo E., Peterson R.A., Campbell A.T., MetroSense Project: People-Centric Sensing at Scale. The 4th ACM Conference on Embedded Networked Sensor Systems, November (2006)

[18] Lundquist J., Cayan D., Dettinger M., Meteorology and Hydrology in Yosemite National Park: A Sensor Network Application. Information Processing in Sensor Networks (IPSN), April (2003).

[19] Werner-Alen G., Lorincz K., Welsh M., Marcillo O., Johnson J., Ruiz M., Lees J., Deploying a Wireless Sensor Network on an Active Volcano. IEEE Computer Society, (2006).

[20] Lindsey S., Raghavendra C., PEGASIS: Power-Efficient Gathering in Sensor Information Systems. IEEE Aerospace Conference Proceedings, (2002).

[21] Rodoplu V., Meng T. H., Mnimum Energy Mobile Wireless Networks. IEEE Journal Selected Areas in Communications, 17 (1999).

[22] Shah R. C., Rabaey J., Energy Aware Routing for Low Energy ad hoc Sensor Networks. IEEE Wireless Communications and Networking Conference, Orlando, (2002).

[23] Michta E., Tendencje rozwojowe $w$ obszarze systemów pomiarowo-sterujacych. Systemy Pomiarowe w Badaniach Naukowych i w Przemyśle, SP'06, Łagowo, (2006), in Polish. 